\title{
Role of TXNDC5 in tumorigenesis of colorectal cancer cells: In vivo and in vitro evidence
}

\author{
FENGBO TAN $^{1}$, HONG ZHU ${ }^{2}$, XIAO HE ${ }^{3}$, NANHUI YU ${ }^{1}$, XINGWEN ZHANG ${ }^{4}$, \\ HAIFAN XU ${ }^{5}$ and HAIPING PEI ${ }^{1}$
}

\begin{abstract}
Departments of ${ }^{1}$ Gastrointestinal Surgery and ${ }^{2}$ Oncology, Xiangya Hospital, Central South University, Changsha, Hunan 410008; ${ }^{3}$ Department of Mammary, Hunan Cancer Hospital, Changsha, Hunan 410013; ${ }^{4}$ Department of Emergency, Hunan Provincial People's Hospital, Changsha, Hunan 410005; ${ }^{5}$ Department of Mammary and Thyroid,

The First Affiliated Hospital of South China University, Hengyang, Hunan 421001, P.R. China
\end{abstract}

Received July 24, 2016; Accepted February 14, 2018

DOI: $10.3892 /$ ijmm.2018.3664

\begin{abstract}
Thioredoxin domain-containing 5 (TXNDC5) is reportedly overexpressed in colorectal cancer (CRC) and is therefore considered an oncogene. However, the role of TXNDC5 in CRC tumorigenesis remains unclear. The present study aimed to explore the role of TXNDC5 in CRC tumorigenesis in vitro and in vivo under hypoxic and normoxic conditions. Analyses of patient tissue samples revealed a positive association between the expression of hypoxia-inducible factor-1 $\alpha$ (HIF-1 $\alpha)$ or TXNDC5 and the TNM stage of CRC. In addition, a positive correlation between the expression levels of HIF-1 $\alpha$ and TXNDC5 was observed in CRC tissues. Furthermore, culturing RKO and HCT-116 human CRC cell lines under hypoxic conditions significantly increased the expression levels of HIF-1 $\alpha$ and TXNDC5, whereas knockdown of HIF-1 $\alpha$ abolished the hypoxia-induced expression of TXNDC5. Knockdown of TXNDC5 significantly decreased cell proliferation and colony formation, and increased apoptosis of both cell lines. Furthermore, knockdown of TXNDC5 markedly increased hypoxia-induced reactive oxygen species (ROS) generation, and the expression of hypoxia-induced endoplasmic reticulum stress (ER) markers (CCAAT-enhancer-binding protein homologous protein, glucose-regulated protein 78 and activating transcription factor 4) and apoptotic markers (B-cell lymphoma 2-associated $X$ protein and cleaved caspase-8). In addition, the expression levels of TXNDC5 were significantly increased in tumor tissues compared with in adenoma and normal tissues in a mouse model of CRC tumorigenesis. In conclusion, the in vivo data demonstrated that TXNDC5 is overexpressed
\end{abstract}

Correspondence to: Professor Haiping Pei, Department of Gastrointestinal Surgery, Xiangya Hospital, Central South University, 87 Xiangya Road, Changsha, Hunan 410008, P.R. China E-mail: peihaiping1966@hotmail.com

Key words: thioredoxin domain-containing 5, colorectal cancer, hypoxia, endoplasmic reticulum stress, tumorigenesis, proliferation, apoptosis in CRC tissues, and this overexpression may be associated with unfavorable clinicopathological features. The in vitro data indicated that hypoxia may induce TXNDC5 expression via upregulating HIF-1 $\alpha$; this effect promoted CRC cell proliferation and survival under hypoxic conditions, likely via inhibiting hypoxia-induced ROS/ER stress signaling. These findings suggested that TXNDC5 functions as an important stress survival factor to maintain tumorigenesis of CRC cells under hypoxia by regulating hypoxia-induced ROS/ER stress signaling. The present study provided novel insights into the role of TXNDC5 in the tumorigenesis of CRC.

\section{Introduction}

Colorectal cancer (CRC) is the third most common type of cancer in China (1). CRC tumorigenesis occurs when mutations accumulate in critical oncogenes and tumor suppressor genes $(2,3)$. Hypoxia is a common feature in numerous solid tumors and the microenvironment is now recognized as a key factor associated with biologically aggressive phenotypes in cancer (4). Hypoxia can induce formation of reactive oxygen species (ROS), which may induce genotoxic effects or cancer cell apoptosis (5). In addition, hypoxia can induce endoplasmic reticulum (ER) stress and activate the unfolded protein response (UPR), which is an adaptive response that increases cancer cell survival under ER stress (6,7). The main pathways of ER stress include three functional components: i) Transcriptional upregulation of specific genes to tackle unfolded and misfolded proteins, namely, the UPR; ii) inhibition of translation to reduce the load of client proteins; and iii) triggering apoptosis when ER functions are severely impaired (8-10).

Thioredoxin domain containing 5 (TXNDC5), which is a member of the disulfide isomerase family, is predominantly expressed in the ER (11). Accumulating evidence has suggested that TXNDC5 is induced by hypoxia in endothelial cells and tumor endothelium (12). It has been reported that TXNDC5 facilitates proteins to fold correctly by the formation of disulfide bonds through its thioredoxin domains (13); this can protect cells from ER stress-induced apoptosis $(12,14)$. In addition to upregulation in numerous types of cancer, including hepatocellular, breast, cervical, esophageal, liver, lung, stomach and uterine carcinoma (15), TXNDC5 is overexpressed 
in CRC $(16,17)$ and is considered an oncogene (18). However, the role of TXNDC5 in CRC tumorigenesis remains unclear.

The present study aimed to explore the role of TXNDC5 in CRC tumorigenesis in vitro and in vivo under hypoxic and normoxic conditions.

\section{Materials and methods}

Patient samples. Tumor and paired normal mucosal tissues were surgically removed from 102 patients with CRC at the Xiangya Hospital of Central South University (Changsha, China) between January 2009 and December 2010. Fresh tissues underwent reverse transcription-quantitative polymerase chain reaction (RT-qPCR) and western blot analysis. The sections were fixed with $4 \%$ polyformaldehyde phosphate buffer for $12 \mathrm{~h}$ at $37^{\circ} \mathrm{C}$. In addition, samples were embedded in paraffin for immunohistochemistry. Normal mucosal tissues were excised $5 \mathrm{~cm}$ away from the tumor. The histomorphology of tumor and normal mucosa were confirmed by pathologists. The present study was approved by the Medical Ethics Committee of Xiangya Hospital and all patients provided written informed consent.

Cell culture and treatment. The human CRC cell lines RKO and HCT-116 reportedly express high levels of HIF-1 $\alpha$ under hypoxia (20). These cell lines were purchased from the American Type Culture Collection (ATCC, Manassas, VA, USA). All cells were cultured in RPMI-1640 medium (Biological Industries, Beit-Haemek, Israel) supplemented with $10 \%$ fetal bovine serum (FBS; Biological Industries). Cells were cultured at $37^{\circ} \mathrm{C}$ in a humidified atmosphere containing $5 \% \mathrm{CO}_{2}$.

RT-qPCR analysis. Total RNA was extracted from cells (RKO and HCT-116 cells) and tissues using TRIzol ${ }^{\circledR}$ reagent (Invitrogen; Thermo Fisher Scientific, Inc., Waltham, MA, USA), and equal amounts of RNA underwent RT-qPCR analysis (PCR kit, SYBR-Green/ROX Mastermix; Takara Bio, Inc., Otsu, Japan) according to the manufacturer's protocol. Firstly, Total RNA underwent DNase treatment with gDNA Eraser buffer and gDNA Eraser. The RNA without DNA was then reversed into cDNA according to the manufacturer's protocol (PrimeScript RT reagent kit with gDNA Eraser; Takara Bio, Inc.). Finally, the cDNA, qPCR reagent (SYBR Premix Ex Taq II; Takara Bio, Inc.) and primer were mixed together for thermocycling, and the thermocycling conditions were according to the manufacturer's operation guidelines as follows: cDNA $2 \mu \mathrm{l}$, qPCR mix $10 \mu \mathrm{l}$, forward primer $0.6 \mu \mathrm{l}$, reverse primer $0.6 \mu 1$, ROX $0.3 \mu 1$, DEPC water, $6.5 \mu 1$, STEP1 $95^{\circ} \mathrm{C} 30 \mathrm{sec}, \mathrm{STEP} 295^{\circ} \mathrm{C} 5 \mathrm{sec}, \mathrm{STEP} 360^{\circ} \mathrm{C} 35 \mathrm{~min}$ STEP4 Go To STEP2 for 30 cycles, STEP5: Melt Curve Stage, STEP6: $4{ }^{\circ} \mathrm{C}$ end. $\beta$-actin was used as an internal control. The primer sequences used are as follows: TXNDC5 (human), sense 5'-GGGTCA AGATCGCCGAAGTA-3', antisense 5'-GCCTCCACTGTGCTCACTGA-3'; TXNDC5 (mouse), sense 5'-CGCACTTCGTCATGTTCTTCG-3', antisense 5'-CAGAGCACACGTCGGAATCA-3'; hypoxia-inducible factor-1 $\alpha$ (HIF-1 $\alpha$ ) (human), sense 5'-ATCGCGGGGACC GATT-3', antisense 5'-CGACGTTCAGAACTTATCTTT TTCTT-3'; and $\beta$-actin, sense 5'-GCACCACACCTTCTACAA
TGAGC-3' and antisense 5'-GGATAGCACAGCCTGGAT AGCAAC-3'. The $2^{-\Delta \Delta \mathrm{Cq}}$ method was used to calculate the relative abundance of mRNA for each gene compared with $\beta$-actin expression (19). Each experiment was performed in triplicate.

Western blot analysis. Tissue samples and cancer cells (RKO and HCT-116 cells) were homogenized and lysed in radioimmunoprecipitation assay buffer (Sigma-Aldrich, St. Louis, MO, USA) supplemented with proteinase inhibitors. Equal amounts of protein $(2 \mu \mathrm{g} / \mu \mathrm{l})$ were loaded and separated by $10 \%$ SDS-PAGE. The protein concentration was determined by BCA. Subsequently, proteins were transferred to a polyvinylidene fluoride membrane (EMD Millipore, Billerica, MA, USA) and the membrane was blocked in $5 \%(\mathrm{w} / \mathrm{v})$ non-fat milk. The membrane was then incubated with primary antibodies overnight at $4^{\circ} \mathrm{C}$, followed by incubation with a secondary antibody (anti-rabbit IgG HRP-linked secondary antibody, 7074S; 1:2,000 dilution; Cell Signaling Technology, Inc., Danvers, MA, USA) for $1 \mathrm{~h}$ at room temperature. Bands were visualized using the Enhanced Chemiluminescence Advance Detection system (EMD Millipore). Blots were semi-quantified using Image Lab V4.0 (Bio-Rad, Hercules, CA, USA). The dilution of primary antibodies were as follows: TXNDC5 (ENT2133), 1:2,000; HIF-1 $\alpha$ (ENT2133), 1:1,000; glucose-regulated protein 78 (GRP78; ENT2245), 1:1,000; CCAAT-enhancer-binding protein homologous protein (CHOP; ENT0911), 1:1,000; activating transcription factor 4 (ATF4; EAP0008), 1:1,000; B-cell lymphoma 2 (Bcl-2)-associated X protein (Bax; ENT0456), 1:1,000; Bcl-2 (ENT0469), 1:500; cleaved caspase-8 (ENC011), 1:1,000; and $\beta$-actin (4970), 1:1,000.

Immunohistochemistry. Tissue slides were prepared as follows: The tissue sections (pruned into 7-10-mm diameter and 5-7 $\mu \mathrm{m}$ thick) were incubated in 3 washes of xylene for 5 min each and then incubated in 2 washes of $100 \%$ ethanol for 10 min each and in 2 washes of $95 \%$ ethanol for 10 min each. The sections were then washed twice in $\mathrm{dH}_{2} \mathrm{O}$ for 5 minutes each and the slides were brought to boil in 1 mM EDTA (pH 8.2) followed by 4 min at a sub-boiling temperature. No cooling was necessary. The sections were washed in $\mathrm{dH}_{2} \mathrm{O} 3$ times for $5 \mathrm{~min}$ each and then incubated in $3 \%$ hydrogen peroxide for $15 \mathrm{~min}$. Afterwards, the sections were washed in $\mathrm{dH}_{2} \mathrm{O}$ twice for $5 \mathrm{~min}$ each. Tissue slides were deparaffinized and antigen retrieval was performed by immersing the slides in boiling EDTA-Tris buffer ( $\mathrm{pH}$ 8.2) for $4 \mathrm{~min}$. Following incubation with $3 \% \mathrm{H}_{2} \mathrm{O}_{2}$ for $15 \mathrm{~min}$, slides were incubated with primary antibodies against TXNDC5 (ENT2133; 1:100) and HIF-1 $\alpha$ (ENT2133; 1:100) (both from Wuhan Elabscience Biotechnology Co., Ltd., Wuhan, China) overnight at $4^{\circ} \mathrm{C}$, followed by incubation with the secondary antibody (SA00004-2; 1:500; Proteintech; Nanjing, China) for $30 \mathrm{~min}$ at room temperature. 3,3'-Diaminobenzidine (0.05\%) was used for 5-10 $\mathrm{min}$ at room temperature to visualize a positive immune reaction. Nuclei were counterstained with hematoxylin. The microscope used was from Leica (Wetzlar, Germany). Briefly, HIF-1 $\alpha$ and TXNDC5 expression levels were scored according to the percentage of positively stained cells and staining intensity: (-) or 0 , no staining (0-10\%); (+) or 1, weak staining (10-25\%); $(++)$ or 2 , moderate staining $(25-50 \%)$ and $(+++)$ or 3 , strong 
Table I. Correlation between clinicopathological features and HIF-1 $\alpha$ or TXNDC5 protein expression in 102 patients with CRC.

\begin{tabular}{|c|c|c|c|c|c|c|c|}
\hline \multirow[b]{2}{*}{$\begin{array}{l}\text { Clinicopathological } \\
\text { variable }\end{array}$} & \multirow[b]{2}{*}{$\mathrm{n}$} & \multicolumn{2}{|c|}{ HIF- $1 \alpha$ expression } & \multirow[b]{2}{*}{ P-value } & \multicolumn{2}{|c|}{ TXNDC5 expression } & \multirow[b]{2}{*}{ P-value } \\
\hline & & $\begin{array}{l}\text { Low } \\
(n=42)\end{array}$ & $\begin{array}{l}\text { High } \\
(n=60)\end{array}$ & & $\begin{array}{l}\text { Low } \\
(n=48)\end{array}$ & $\begin{array}{l}\text { High } \\
(n=54)\end{array}$ & \\
\hline Age (years) & & & & 1.000 & & & 0.099 \\
\hline$<60$ & 63 & $26(41.3 \%)$ & $37(58.7 \%)$ & & $26(41.3 \%)$ & $37(58.7 \%)$ & \\
\hline$\geq 60$ & 39 & $16(41.0 \%)$ & $23(59.0 \%)$ & & $22(56.4 \%)$ & $17(43.6 \%)$ & \\
\hline Gender & & & & 0.432 & & & 0.843 \\
\hline Male & 58 & $26(44.8 \%)$ & $32(55.2 \%)$ & & $28(48.3 \%)$ & $30(51.7 \%)$ & \\
\hline Female & 44 & $16(36.4 \%)$ & $28(63.6 \%)$ & & $20(45.5 \%)$ & $24(54.5 \%)$ & \\
\hline Location & & & & 0.329 & & & 0.424 \\
\hline Left colon & 38 & $19(50.0 \%)$ & $19(50.0 \%)$ & & $21(55.3 \%)$ & $17(44.7 \%)$ & \\
\hline Right colon & 25 & $10(40.0 \%)$ & $15(60.0 \%)$ & & $10(40.0 \%)$ & $15(60.0 \%)$ & \\
\hline Rectum & 39 & $13(33.3 \%)$ & $26(66.7 \%)$ & & $17(43.6 \%)$ & $22(56.4 \%)$ & \\
\hline Size $(\mathrm{cm})$ & & & & 0.687 & & & 1.000 \\
\hline$<5.0$ & 47 & $19(38.3 \%)$ & $28(61.7 \%)$ & & $22(46.8 \%)$ & $25(53.2 \%)$ & \\
\hline$\geq 5.0$ & 55 & $24(43.6 \%)$ & $31(56.4 \%)$ & & $26(47.3 \%)$ & $29(52.7 \%)$ & \\
\hline Differentiation & & & & 0.510 & & & 0.661 \\
\hline Well-moderate & 74 & $29(39.2 \%)$ & $45(60.8 \%)$ & & $36(48.6 \%)$ & $38(51.4 \%)$ & \\
\hline Poor & 28 & $13(46.4 \%)$ & $15(53.6 \%)$ & & $12(42.9 \%)$ & $16(57.1 \%)$ & \\
\hline CEA & & & & 0.071 & & & 0.824 \\
\hline$<5 \mathrm{ng} / \mathrm{ml}$ & 75 & $35(46.7 \%)$ & $40(53.3 \%)$ & & $36(48.0 \%)$ & $39(52.0 \%)$ & \\
\hline$\geq 5 \mathrm{ng} / \mathrm{ml}$ & 27 & $7(25.9 \%)$ & $20(74.1 \%)$ & & $12(44.4 \%)$ & $15(55.6 \%)$ & \\
\hline Adjuvant therapy & & & & 0.384 & & & 0.667 \\
\hline Yes & 31 & $15(48.4 \%)$ & $16(51.6 \%)$ & & $16(51.6 \%)$ & $15(48.4 \%)$ & \\
\hline No & 71 & $27(38.0 \%)$ & $44(62.0 \%)$ & & $32(45.1 \%)$ & $39(54.9 \%)$ & \\
\hline TNM stage & & & & $0.008^{\mathrm{a}}$ & & & $0.027^{\mathrm{a}}$ \\
\hline I-II & 29 & $18(62.1 \%)$ & $11(37.9 \%)$ & & $19(65.5 \%)$ & $10(34.5 \%)$ & \\
\hline III & 73 & $24(32.9 \%)$ & $49(67.1 \%)$ & & $29(39.7 \%)$ & $44(60.3 \%)$ & \\
\hline T stage & & & & $0.036^{\mathrm{a}}$ & & & $0.035^{\mathrm{a}}$ \\
\hline $\mathrm{T} 1-\mathrm{T} 2$ & 13 & $9(69.2 \%)$ & $4(30.8 \%)$ & & $10(76.9 \%)$ & $3(23.1 \%)$ & \\
\hline $\mathrm{T} 3-\mathrm{T} 4$ & 89 & $33(37.1 \%)$ & $56(62.9 \%)$ & & $38(42.7 \%)$ & $51(57.3 \%)$ & \\
\hline $\mathrm{N}$ stage & & & & $0.023^{\mathrm{a}}$ & & & $0.045^{\mathrm{a}}$ \\
\hline NO & 28 & $17(60.7 \%)$ & $11(39.3 \%)$ & & $18(64.3 \%)$ & $10(35.7 \%)$ & \\
\hline N1-N2 & 74 & $25(33.8 \%)$ & $49(66.2 \%)$ & & $30(40.5 \%)$ & $44(59.5 \%)$ & \\
\hline
\end{tabular}

HIF-1 $\alpha$ and TXNDC5 expression in CRC tissues was examined by immunohistochemistry and scored according to the percentage of positively stained cells and staining intensity: (-) or 0, no staining (0-10\%); (+) or 1, weak staining (10-25\%); (++) or 2, moderate staining (25-50\%); and $(+++)$ or 3 , strong staining $(>50 \%)$. (-) and $(+)$ were defined as low expression, and $(++)$ and $(+++)$ were defined as high expression. ${ }^{a} \mathrm{P}<0.05$. CEA, carcinoembryonic antigen; CRC, colorectal cancer; HIF-1 $\alpha$, hypoxia-inducible factor- $1 \alpha$; TXNDC5, thioredoxin domain-containing 5.

staining (>50\%). (-) and (+) were defined as low expression, and $(++)$ and $(+++)$ were defined as high expression. The staining results were independently evaluated by two board-certified clinical pathologists blinded to the clinical parameters. Any discrepancy between the two evaluators was resolved by re-evaluation and careful discussion until agreement was reached.

Hypoxia treatment [ $1 \% \mathrm{O}_{2}$ or cobalt chloride $\left.\left(\mathrm{CoCl}_{2}\right)\right]$. Cells were cultured in 96-well plates, or $60-$ or $100-\mathrm{mm}$ petri dishes. For each assay, RKO and HCT-116 cells were cultured in RPMI-1640 containing 10\% FBS for 24 h. For hypoxic treatment, cells were exposed to either $1 \% \mathrm{O}_{2}$ or to various concentrations of the hypoxia-mimicking agent $\mathrm{CoCl}_{2}$ (PhytoTechnology Laboratories, Lenexa, KS, USA) for various time intervals, as previously described (21).

MTT cell proliferation assay. In vitro cell proliferation was determined using a MTT Cell Proliferation Assay kit (ATCC) according to the manufacturer's protocol. Briefly, cells were plated at $15 \times 10^{3}$ cells/well in 96-well tissue culture plates. At the end of the culture period, cells were washed with PBS, and the MTT reagents were added according to the manufacturer's protocol. Subsequently, formazan was dissolved using DMSO 
and the absorbance was then measured at $570 \mathrm{~nm}$ using an ELISA plate reader. Each experiment was repeated three times in triplicate.

Colony formation assay. Cells were seeded at a density of 500 cells/6-well plates (Corning Inc., Corning, NY, USA) in triplicate and were cultured for 14 days. During colony growth assays, the culture medium was replaced every 3 days. Colonies with $>50$ cells were counted when visible to naked eye and stained with GIEMSA under a light microscope.

Cell apoptosis assay. Cells were seeded at $1 \times 10^{5}$ cells/well in 96-well tissue culture plates. Cell apoptosis was measured at $24 \mathrm{~h}$ using a microplate reader-based TiterTACS in situ apoptosis detection kit (R\&D Systems, Inc., Minneapolis, MN, USA) according to the manufacturer's protocol. The percentage of apoptotic cells was calculated.

Measurement of ROS. The intracellular total ROS Activity Assay kit (Abnova, Walnut, CA, USA) was used to detect ROS levels, according to the manufacturer's protocol. Briefly, the treated cells were lysed and the amount of intracellular ROS was calculated according to dichlorodihydrofluorescein production, which was measured using a fluorometric plate reader at excitation and emission wavelengths of 490 and $525 \mathrm{~nm}$, respectively.

Transient transfection of small interfering (si)RNA. Cells (3.0x $10^{5}$ per well) were seeded into 24 -well plates at a density of $1.5 \times 10^{5}$ cells $/ \mathrm{ml}$, and allowed to reach $\sim 50 \%$ confluence on the day of transfection. Cells were transfected with $100 \mathrm{nmol} / \mathrm{l}$ of each siRNA duplex for $6 \mathrm{~h}$ at $37^{\circ} \mathrm{C}$ using Lipofectamine ${ }^{\circledR} 2000$ reagent (Invitrogen; Thermo Fisher Scientific,Inc.) according to the manufacturer's protocol. Scrambled control siRNA (siScr), siHIF-1 $\alpha$ (AGCCATTTACATAATATAGAA) and siTXNDC5 (ATCGAGCTACTTCCCATAATA) were all purchased from Guangzhou RiboBio Co., Ltd. (Guangzhou, China).

Azoxymethane (AOM)-induced colorectal tumorigenesis model. AOM was used to induce a sporadic colorectal tumorigenesis model, as previously described (22). Briefly, 8 week-old male mice $[\mathrm{n}=18 ; \mathrm{A} / \mathrm{J}$ strain; divided into 3 groups; weight, $>18 \mathrm{~g}$; maintenance conditions: temperature, $18-29^{\circ} \mathrm{C}$; relative humidity, $50-60 \%$; free access to clean food and water; lighting for 10-14 h (lights turned on at 8:00 every day and turned off at 18:00)] were intraperitoneally injected with $10 \mathrm{mg} / \mathrm{kg}$ body weight AOM (Sigma-Aldrich) six times. The mice were injected with AOM every week from the first to the sixth week. The mice were then provided with regular water and did not undergo any further treatment. Mice were sacrificed at various time-points, after which the colorectum was excised, opened longitudinally, flushed with ice-cold PBS and fixed in 10\% formalin/PBS for $24 \mathrm{~h}$ at room temperature. Subsequently, macroscopic tumors were counted and morphological evaluation of normal, adenoma and tumor tissues were performed under a light microscope. All mice were divided into 3 groups; the blank control group was treated with normal saline, the adenoma and tumor groups were treated with AOM. The normal tissues were obtained from the blank control group, and the adenoma tissues were obtain from mice treated with AOM at the end of the 12th week. All animals received humane care according to the Institutional Animal Care and Treatment Committee of Central South University, and the proof number of ethics was 201603426.

Statistical analysis. Statistical analysis of the differences in mRNA expression levels of HIF-1 $\alpha$ and TXNDC5 between paired tissues were analyzed by paired t-test. The association between target gene expression and clinicopathological factors was estimated by $\chi^{2}$ test. The statistical differences among $\geq 2$ groups were analyzed using one-way analysis of variance followed by post hoc pairwise comparisons (Tukey's post hoc test). The experiments were repeated 3 times. The correlation between HIF- $1 \alpha$ and TXNDC5 expression was determined by Spearman's correlation analysis. All data are expressed as the means \pm standard error. $\mathrm{P}<0.05$ was considered to indicate a statistically significant difference. The statistical software programs GraphPad Prism 6.0 (GraphPad Software, Inc., La Jolla, CA, USA) and SPSS 13.0 for Windows (SPSS, Inc., Chicago, IL, USA) were used to analyze data.

\section{Results}

TXNDC5 upregulation is associated with HIF-1 $\alpha$ overexpression in human CRC specimens. The expression levels of HIF- $1 \alpha$ and TXNDC5 were detected in CRC tissues from patients. As shown in Fig. 1A, the mRNA expression levels of HIF- $1 \alpha$ and TXNDC5 were increased in CRC tissues compared with in paired normal mucosal tissues. In addition, TXNDC5 mRNA expression was positively correlated with HIF-1 $\alpha$ mRNA expression in CRC tissues $(r=0.435$, $\mathrm{P}<0.0001)$. The protein expression levels of HIF- $1 \alpha$ and TXNDC5 were detected in randomly selected CRC samples by western blot analyses. As shown in Fig. 1B, CRC tissues exhibited higher expression levels of TXNDC5 compared with in paired normal tissues. As presented in Fig. 1C, analyses of the staining intensity in immunohistochemistry images indicated that the expression of TXNDC5 was highly correlated with the expression of HIF-1 $\alpha$ in CRC tissues ( $\mathrm{r}=20.508, \mathrm{P}<0.0001$; data not shown). In addition, strong HIF-1 $\alpha$ and TXNDC5 staining was revealed to be associated with advanced TNM stage (Fig. 1D). As shown in Table I, the expression levels of HIF-1 $\alpha$ and TXNDC5 were significantly associated with the TNM stage of CRC, whereas no significant association was found with other clinicopathological variables, including age, gender, tumor location, tumor size, tumor differentiation, adjuvant therapy and carcinoembryonic antigen levels.

Hypoxia induces the expression of TXNDC5 via upregulating HIF-1 $\alpha$ in CRC cell lines. To examine whether HIF-1 $\alpha$ induced the expression of TXNDC5, RKO and HCT-116 human CRC cells were cultured under hypoxic conditions $\left(1 \% \mathrm{O}_{2}\right)$ in a sealed hypoxic chamber (23). As shown in Fig. 2A, the expression levels of HIF-1 $\alpha$ and TXNDC5 reached a peak after $24 \mathrm{~h}$ under hypoxia. The cells were also treated with various concentrations of $\mathrm{CoCl}_{2}$, which is 

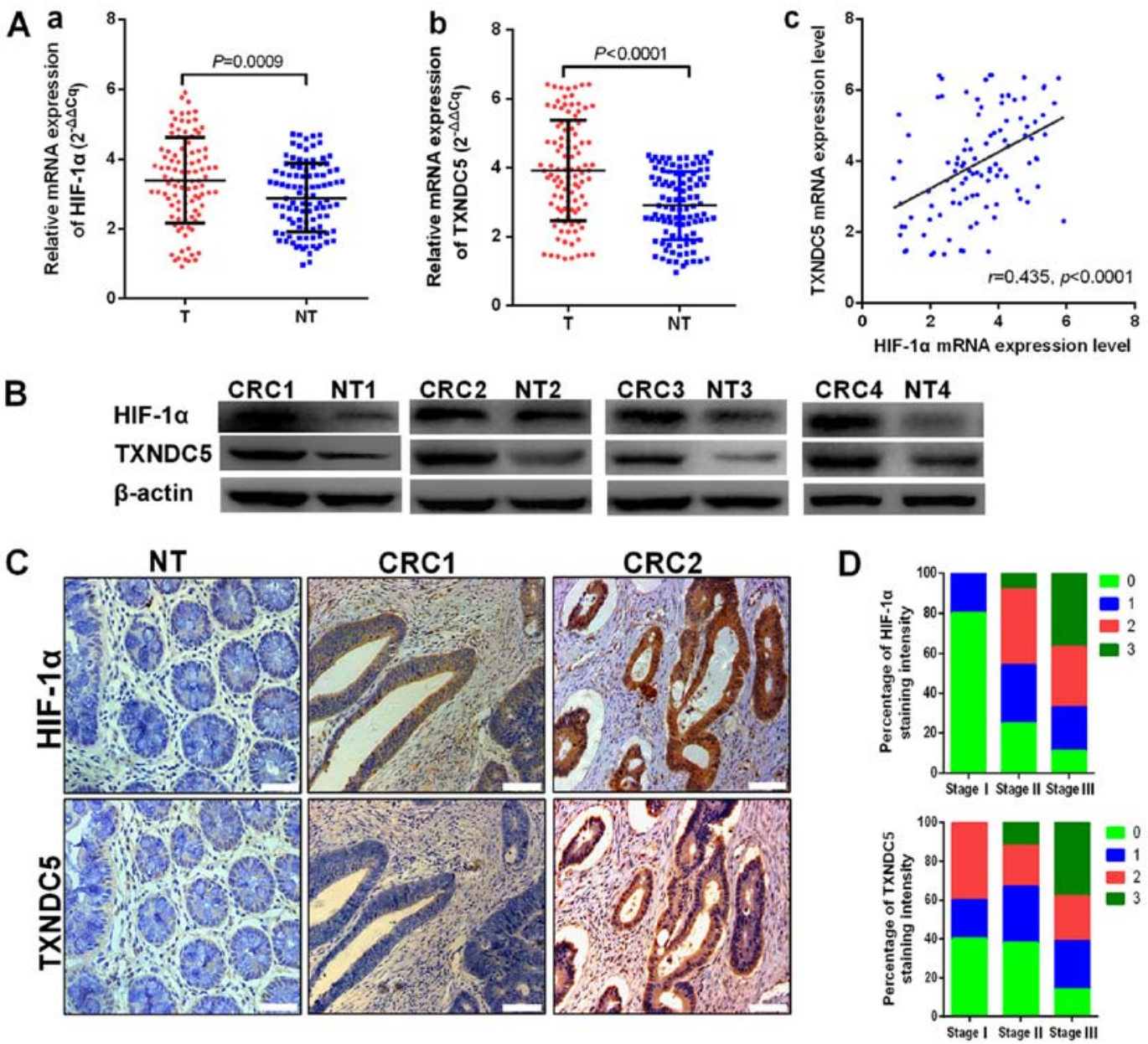

Figure 1. TXNDC5 upregulation is associated with HIF-1 $\alpha$ overexpression in human CRC tissues. (A) mRNA expression levels of (a) HIF-1 $\alpha$ and (b) TXNDC5 in T and NT were detected by reverse transcription-quantitative polymerase chain reaction in patients with CRC. (c) TXNDC5 mRNA expression was positively correlated with HIF-1 $\alpha$ mRNA expression $(r=0.435$, P<0.0001). (B) Western blot analyses were used to detect the protein expression levels of HIF-1 $\alpha$ and TXNDC5 in randomly selected CRC tissues and NT. (C) Expression levels of HIF-1 $\alpha$ and TXNDC5 were examined by immunohistochemistry in CRC tissues and NT from 102 patients with CRC. Images show negative staining of HIF-1 $\alpha$ and TXNDC5 in NT; negative or low staining of HIF-1 $\alpha$ and TXNDC5 in CRC1; and strong staining of HIF-1 $\alpha$ and TXNDC5 in CRC2. Magnification, x200; scale bar, $100 \mu \mathrm{m}$. (D) Strong staining of HIF-1 $\alpha$ and TXNDC5 was associated with advanced TNM stage. Scores indicate staining intensity: 0 , negative; 1 , weak staining; 2 , intermediate staining; and 3, strong staining. CRC, colorectal cancer; HIF-1 $\alpha$, hypoxia-inducible factor-1 $\alpha$; NT, paired normal tissues; T, tumor tissues; TXNDC5, thioredoxin domain-containing 5.

a HIF prolyl hydroxylase antagonist (24) that was used as a positive control for HIF-1 $\alpha$ induction. As shown in Fig. 2B, $1 \mu \mathrm{M} \mathrm{CoCl}_{2}$ induced the highest expression of TXNDC5; similar results were observed with regards to the expression of HIF-1 $\alpha$. Subsequently, a specific siRNA (siHIF-1 $\alpha$ ) was used to knockdown HIF- $1 \alpha$ by $\sim 65 \%$ in RKO cells and $\sim 55 \%$ in HCT-116 cells under hypoxic conditions. As shown in Fig. 3, knockdown of HIF-1 $\alpha$ abolished the hypoxia-induced expression of TXNDC5 in RKO and HCT-116 cells.

TXNDC5 is critical for CRC tumorigenesis under hypoxia. To determine the function of TXNDC5, a specific siRNA (siTXNDC5) was used to knockdown TXNDC5 expression by $\sim 60 \%$ in RKO and HCT-116 cells under hypoxic conditions (Fig. 4). To determine the effects of TXNDC5 on cell proliferation, the MTT assay was performed on cells transfected with siTXNDC5 or siScr. As shown in Fig. 5A, TXNDC5 knockdown resulted in a significant reduction in the proliferation of both cell lines under hypoxia, but not under normoxia. Furthermore, cells transfected with siTXNDC5 exhibited a $\sim 75 \%$ reduction in colony-forming capacity compared with in those transfected with siScr under hypoxic conditions, but not normoxic conditions (Fig. 5B and $\mathrm{C}$ ). These findings suggested that TXNDC5 was critical for CRC cell proliferation under hypoxia. Furthermore, the role of siTXNDC5 was determined in hypoxia-induced CRC cell apoptosis. As shown in Fig. 5D, knockdown of TXNDC5 significantly increased cell apoptosis under hypoxia, but not under normoxia, thus suggesting a protective role of TXNDC5 in hypoxia-induced CRC cell apoptosis. The present study also examined the expression levels of TXNDC5 in an AOM-induced mouse model of CRC tumorigenesis, which reportedly exhibits similar pathological and pathophysiological manifestations to human sporadic colorectal tumorigenesis (22). As shown in Fig. 6, the mRNA and protein expression levels of TXNDC5 were significantly increased in tumor tissues compared with in adenoma and normal tissues, confirming the important role of TXNDC5 in CRC tumorigenesis. 
A

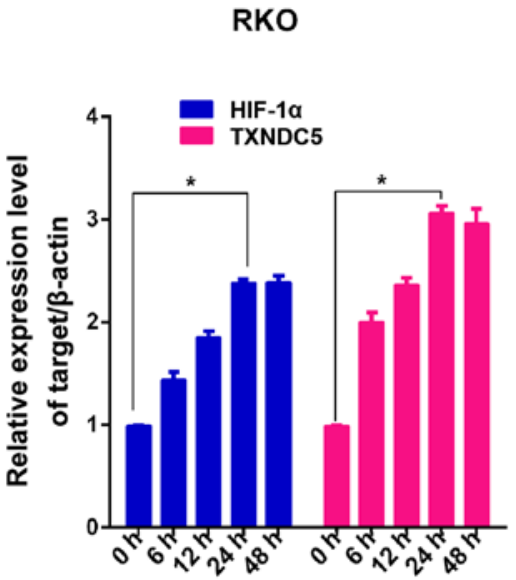

Hypoxia:

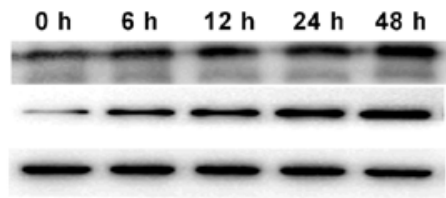

B

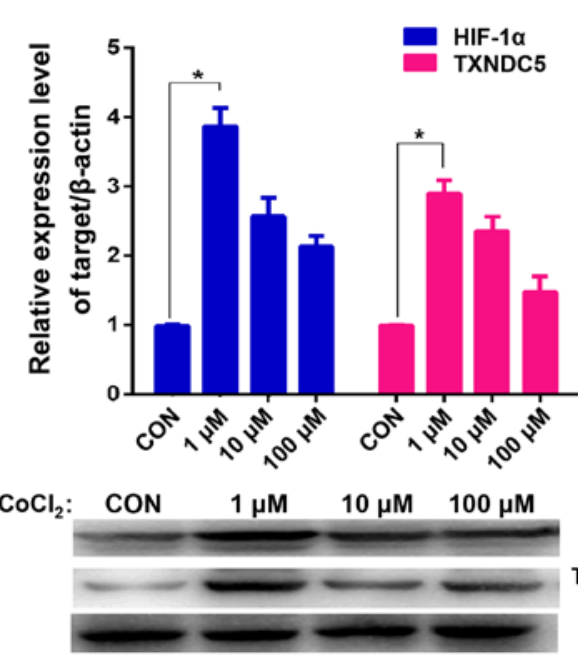

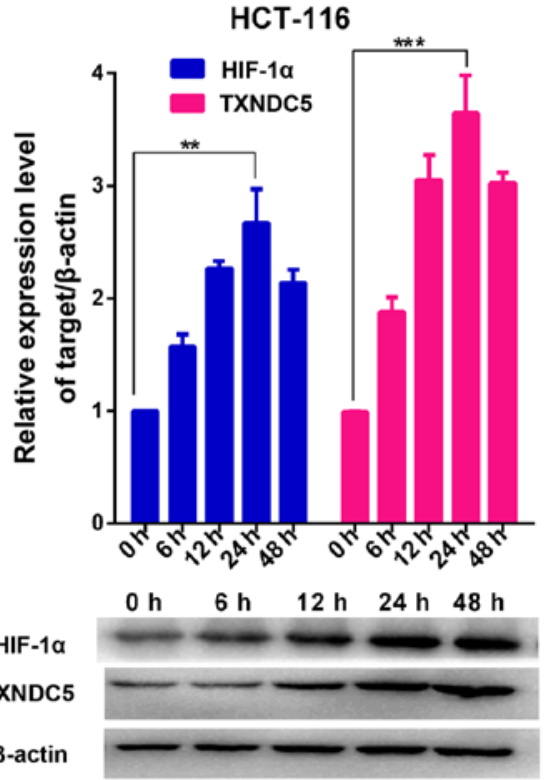

HCT-116

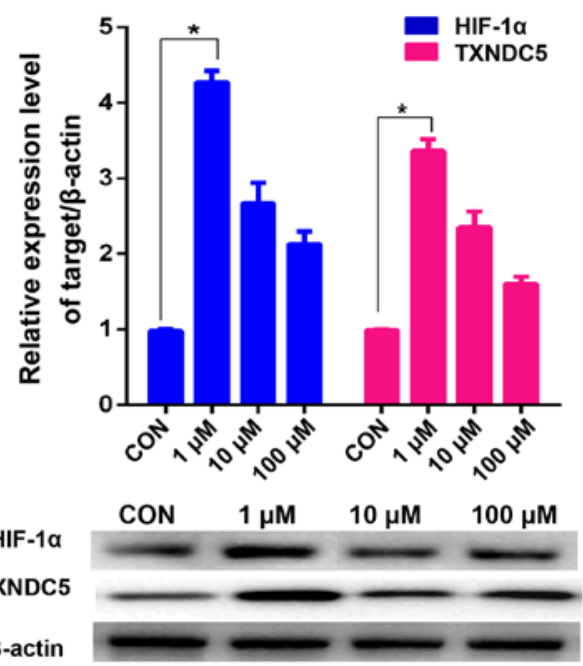

Figure 2. TXNDC5 expression is increased in CRC cells during hypoxia. (A) Western blot analyses were used to detect the protein expression levels of HIF-1 $\alpha$ and TXNDC5 in RKO and HCT-116 CRC cells under hypoxia $\left(1 \% \mathrm{O}_{2}\right)$. $\beta$-actin was used as a loading control. Density of the HIF-1 $\alpha$ or TXNDC5 blot was normalized against that of the $\beta$-actin blot, in order to obtain relative blot density, which was expressed as a fold change to that of the control ( $0 \mathrm{~h}$ ) (designated as 1$)$. ${ }^{*} \mathrm{P}<0.0001{ }^{* * *} \mathrm{P}=0.0007$ and ${ }^{* * * *} \mathrm{P}=0.0002$. (B) RKO and HCT-116 cells were treated with 1,10 or $100 \mu \mathrm{M} \mathrm{CoCl} \mathrm{l}_{2}$ for $48 \mathrm{~h}$. Western blot analyses were used to detect the protein expression levels of HIF-1 $\alpha$ and TXNDC5. $\beta$-actin was used as a loading control. Density of the HIF-1 $\alpha$ or TXNDC5 blot was normalized against that of the $\beta$-actin blot, in order to obtain relative blot density, which was expressed as a fold change to that of the control (untreated cells) (designated as 1). ${ }^{*} \mathrm{P}<0.0001$. $\mathrm{CoCl}_{2}$, cobalt chloride; $\mathrm{CON}$, control; $\mathrm{CRC}$, colorectal cancer; HIF-1 $\alpha$, hypoxia-inducible factor-1 $\alpha$; TXNDC5, thioredoxin domain-containing 5 .

Knockdown of TXNDC5 aggravates ER stress and induces apoptosis in CRC cell lines. Hypoxia can induce the formation of ROS, which are critical inducers of ER stress (5-7). Therefore, the present study examined the effects of TXNDC5 knockdown on the production of ROS in RKO and HCT-116 cells. As shown in Fig. 7A, cells transfected with siTXNDC5 exhibited significantly increased ROS production compared with those transfected with siScr under hypoxic, but not normoxic conditions. As shown in Fig. 7B, hypoxia significantly induced the expression of ER stress (CHOP, GRP78 and ATF4), apoptosis (Bax and cleaved caspase-8) and survival (Bcl-2) markers in RKO and HCT-116 cells, whereas knockdown of TXNDC5 further increased the expression of ER stress (CHOP, GRP78 and ATF4) and apoptosis (Bax and cleaved caspase-8) markers under hypoxic, but not normoxic conditions. Conversely, knockdown of TXNDC5 significantly decreased hypoxia-induced expression of the survival marker Bcl-2 under hypoxia, but not under normoxia.

\section{Discussion}

Numerous studies, including our previous comparative proteomic study, demonstrated that TXNDC5 is overexpressed in CRC (15-17). The present study provided in vivo and in vitro evidence to suggest that TXNDC5 serves an important role in the tumorigenesis of CRC, particularly under hypoxia. The present in vivo data indicated a positive association between 

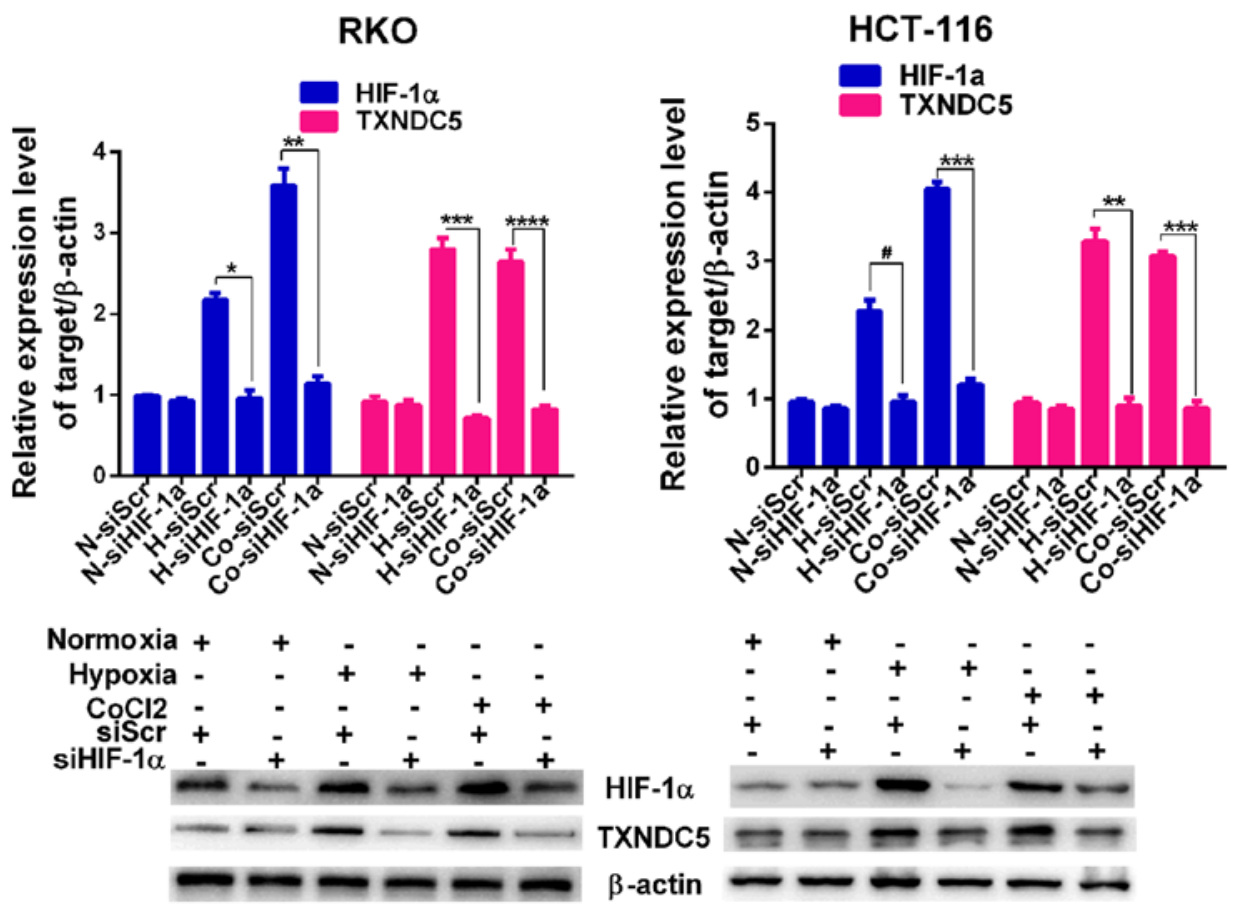

Figure 3. TXNDC5 expression is regulated by HIF-1 $\alpha$ in CRC cells. RKO and HCT-116 cells were transfected with a specific siRNA (siHIF-1 $\alpha$ ) to knockdown HIF-1 $\alpha$. Cells transfected with siScr were used as a control. The expression levels of HIF-1 $\alpha$ and TXNDC5 were detected by western blotting in cells under $\mathrm{N}, 24 \mathrm{~h} \mathrm{H}$ and $\mathrm{CoCl}_{2}$ treatment $(1 \mu \mathrm{M} ; 48 \mathrm{~h})$. $\beta$-actin was used as a loading control. Density of the HIF-1 $\alpha$ or TXNDC5 blot was normalized against that of the $\beta$-actin blot, in order to obtain relative blot density, which was expressed as a fold change to that of cells transfected with siScr under normoxia (N-siScr) (designated as 1). ${ }^{*} \mathrm{P}=0.0009 ;{ }^{* *} \mathrm{P}=0.0004 ;{ }^{* * *} \mathrm{P}=0.0001 ;{ }^{* * * * *} \mathrm{P}=0.0004 ;{ }^{*} \mathrm{P}=0.0019 . \mathrm{CoCl}_{2}$, cobalt chloride; $\mathrm{CRC}$, colorectal cancer; $\mathrm{H}$, hypoxia; HIF-1 $\alpha$, hypoxia-inducible factor-1 $\alpha$; N, normoxia; siRNA/si, small interfering RNA; siScr, scrambled control siRNA; TXNDC5, thioredoxin domain-containing 5 .

\section{RKO}

$\begin{array}{rcccc}\text { Normoxia } & + & + & - & - \\ \text { Hypoxia } & - & - & + & + \\ \text { siScr } & + & - & + & - \\ \text { siTXNDC5 } & - & + & - & +\end{array}$

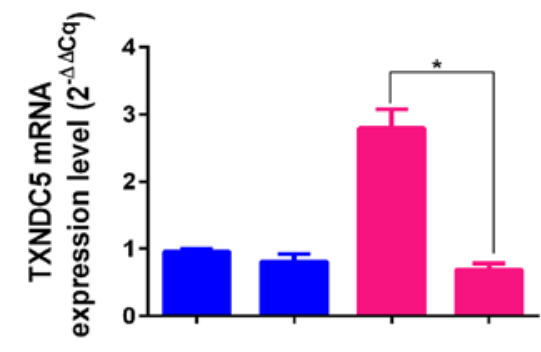

\section{TXNDC5}

$\beta$-actin

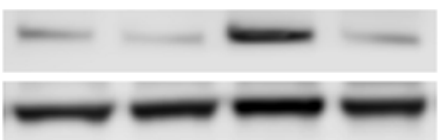

НCT-116
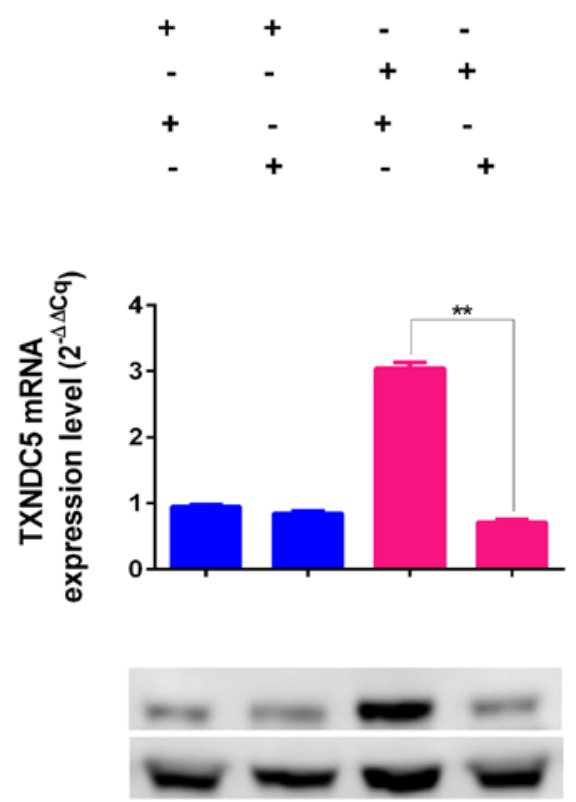

Figure 4. Knockdown of TXNDC5 in colorectal cancer cells. RKO and HCT-116 cells were transfected with a specific siRNA (siTXNDC5) to knockdown TXNDC5. Cells transfected with siScr were used as a control. The expression levels of TXNDC5 were detected by reverse transcription-quantitative polymerase chain reaction and western blot analyses under $\mathrm{H}$ or $\mathrm{N}$. " $\mathrm{P}=0.0003$; ** $\mathrm{P}<0.0001$. $\mathrm{H}$, hypoxia; HIF-1 $\alpha$, hypoxia-inducible factor-1 $\alpha$; $\mathrm{N}$, normoxia; siRNA/ si, small interfering RNA; siScr, scrambled control siRNA; TXNDC5, thioredoxin domain-containing 5.

TXNDC5 and the TNM stage of CRC in human samples; this was corroborated by the sporadic CRC animal model, which exhibited an ascending tendency in the expression levels of
TXNDC5 from normal to CRC tissues. The in vitro data indicated that TXNDC5 could promote proliferation and survival of CRC cells under hypoxia, likely by regulating ER stress. 
A

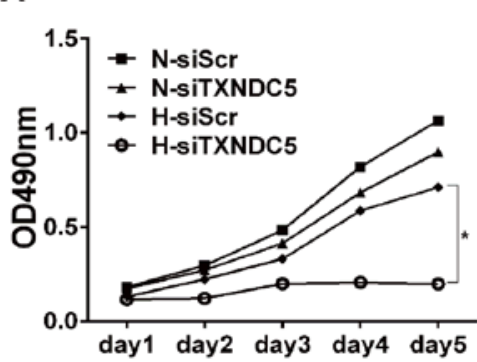

B

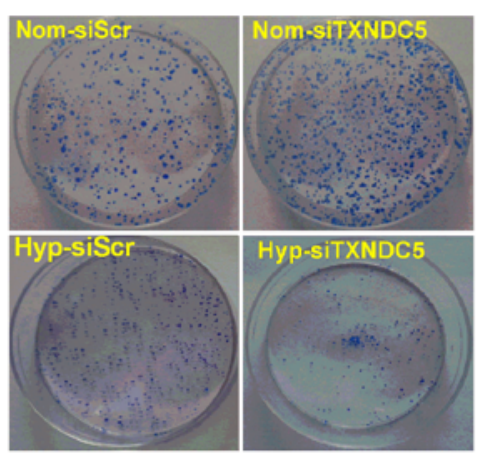

C

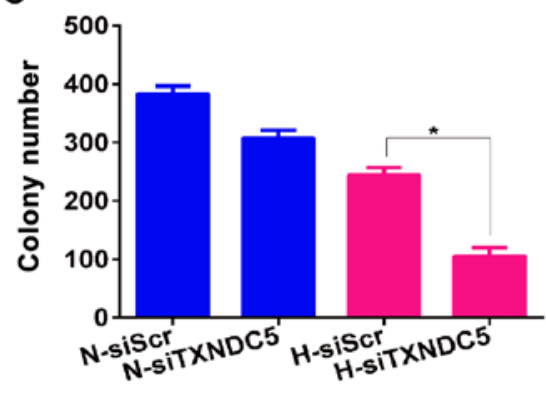

。

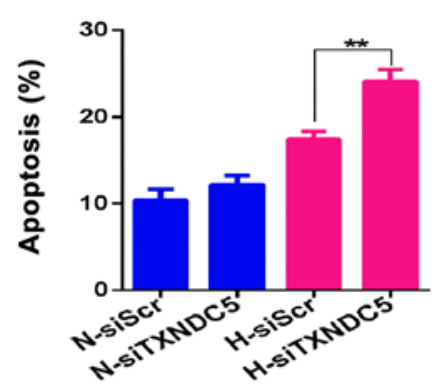

HCT-116
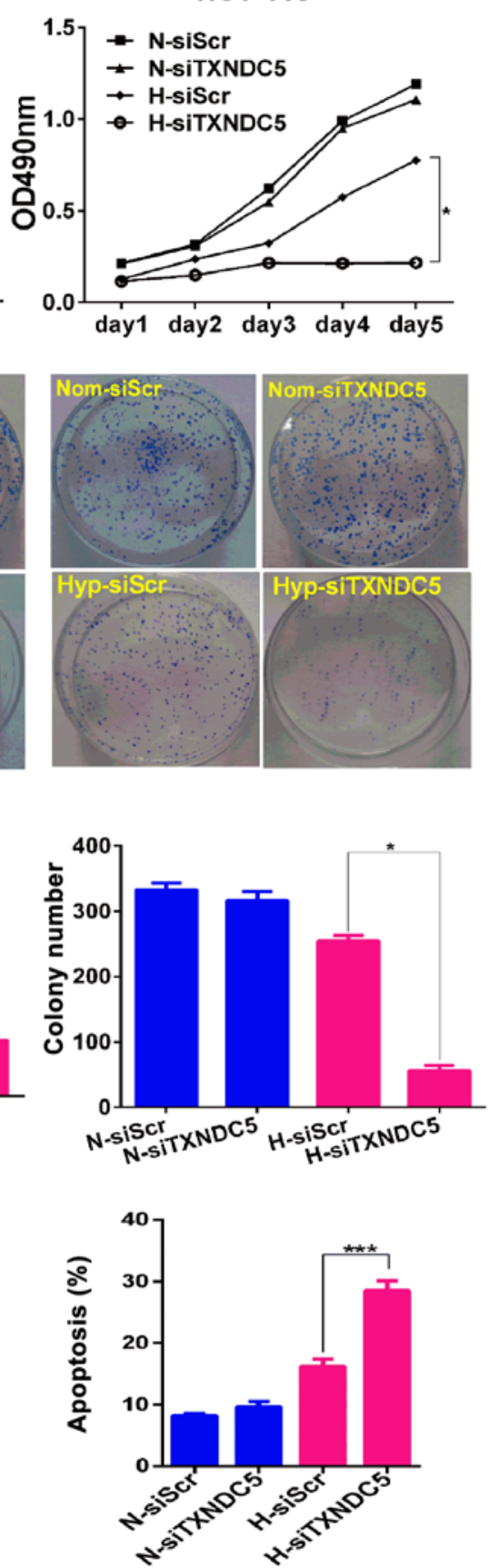

Figure 5. TXNDC5 promotes colorectal cancer cell proliferation, colony formation and survival in vitro. RKO and HCT-116 cells were transfected with a specific siRNA (siTXNDC5) to knockdown TXNDC5. Cells transfected with siScr were used as a control. (A) MTT assays ( $\left.{ }^{*}<0.0001\right)$, (B and C) colony formation assays( $\left({ }^{*} \mathrm{P}<0.0001\right)$ and $(\mathrm{D})$ apoptosis assays $\left({ }^{* *} \mathrm{P}=0.0020 ;{ }^{* * *} \mathrm{P}=0.0004\right)$ were performed in RKO and HCT-116 cells transfected with siTXNDC5 or siScr under H and N. H/Hyp, hypoxia; N/Nom, normoxia; OD, optical density; siRNA/si, small interfering RNA; siScr, scrambled control siRNA; TXNDC5, thioredoxin domain-containing 5 .

It has previously been reported that TXNDC5 promotes cell proliferation under hypoxic conditions, including in fibroblast-like cells, synovial fluid and blood (25). In addition, hypoxia-induced TXNDC5 has been demonstrated to protect endothelial cells and tumor endothelium from hypoxia-induced apoptosis (12); however, these previous studies did not indicate whether TXNDC5 was regulated by hypoxia. In the present study, in CRC cells, hypoxia induced the expression of TXNDC5 via HIF-1 $\alpha$; HIF-1 $\alpha$ knockdown abolished hypoxia-induced expression of TXNDC5. A previous study reported that hypoxia exerted no detectable effects on TXNDC5 expression in non-small cell lung cancer cell lines under hypoxia, whereas HIF-1 $\alpha$ was upregulated (26). This discrepancy may be attributed to the fact that the cells were obtained from different organs with varying genetic backgrounds.

Previous studies have demonstrated that hypoxia regulates the expression of genes involved in angiogenesis, anaerobic glycolysis, cell proliferation and survival $(27,28)$. The present study revealed that TXNDC5 knockdown decreased CRC cell 


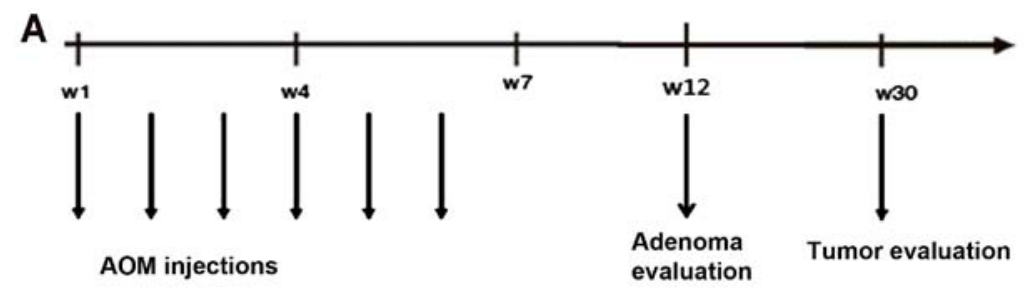

B
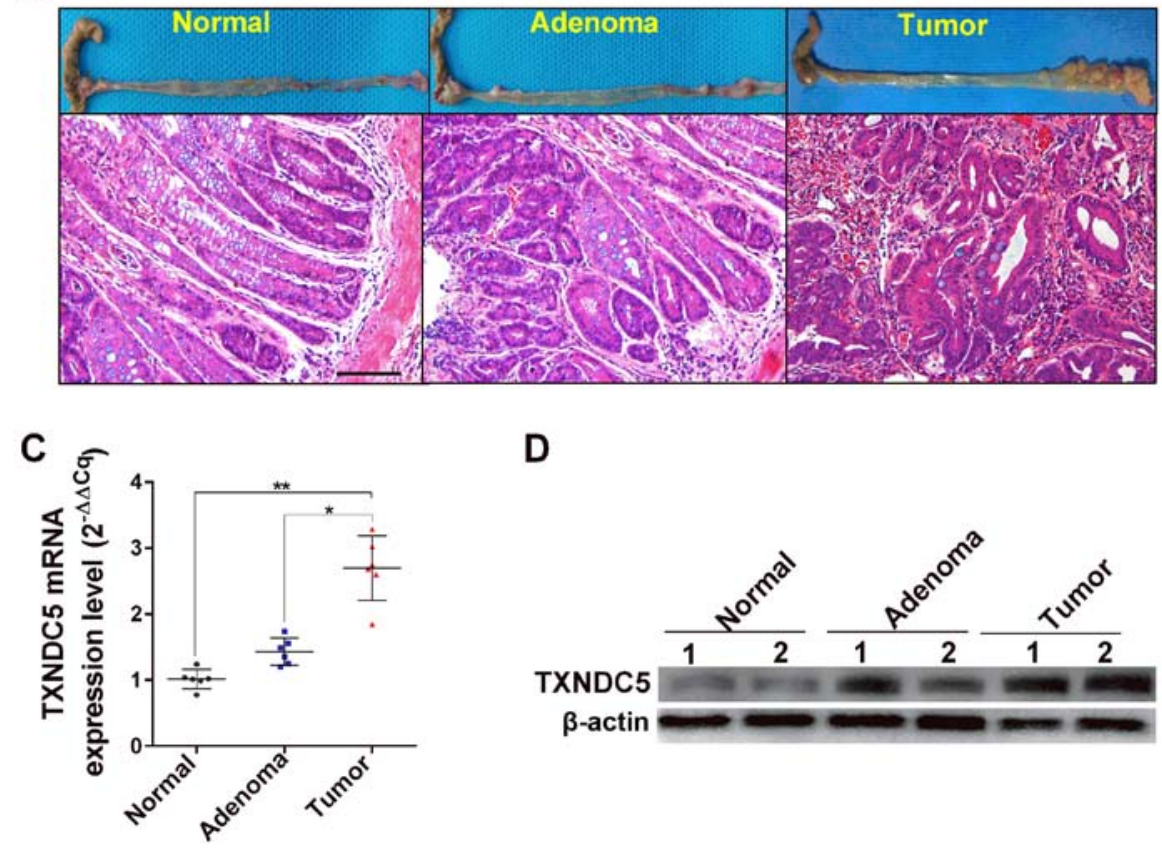

D

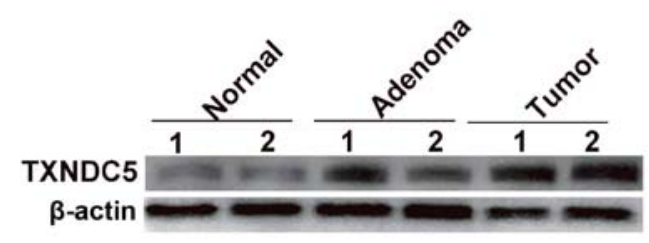

Figure 6. TXNDC5 expression was increased during CRC progression. TXNDC5 expression was examined by RT-qPCR and western blotting in an AOM-induced mouse model of CRC. (A) Schematic diagram of the experimental course of AOM-induced colorectal carcinogenesis, used to mimic human sporadic colorectal cancer. (B) Macroscopic tumor and microstructure morphological evaluation of normal tissue, adenoma and tumor. Magnification, x200; scale bar, $100 \mu \mathrm{m}$. mRNA and protein expression levels of TXNDC5 were detected by (C) RT-qPCR and (D) western blot analyses. "P=0.0002; ** $\mathrm{P}<0.0001$. AOM, azoxymethane; CRC, colorectal cancer; RT-qPCR, reverse transcription-quantitative polymerase chain reaction; TXNDC5, thioredoxin domain-containing 5 .

proliferation and colony formation, and augmented apoptosis under hypoxia, thus suggesting that TXNDC5 is critical for CRC cell proliferation and survival under hypoxic conditions. Previous studies have also demonstrated that TXNDC5 regulates proliferation and survival of gastric and pancreatic cancer cells under normoxia $(29,30)$. However, in the present study, knockdown of TXNDC5 only affected CRC cell proliferation and survival under hypoxia, not normoxia. These findings suggested that TXNDC5 is more likely a hypoxia-induced stress survival factor rather than a common oncogene in CRC.

Hypoxia induces ROS production and ER stress $(10,31,32)$. ROS directly or indirectly affects ER homeostasis and protein folding, which triggers ER stress and may induce cell apoptosis in the case of excessive ER stress $(32,33)$. Accumulating evidence has suggested that TXNDC5 is involved in ROS production and ER stress $(30,34)$. It has previously been reported that inhibiting the expression of TXNDC5 via knockdown of the orphan nuclear receptor, nuclear receptor subfamily 4 group A member 1,induces ROS and ER stress in pancreatic cancer cells (30); conversely, increasing the expression of TXNDC5 in lipid endothelial cells effectively decreases ROS production and protects cells (34). The present study demonstrated that, in CRC cells, knockdown of TXNDC5 markedly increased hypoxia-induced ROS production, and the expression of hypoxia-induced ER stress and apoptotic markers. This finding is in agreement with a previous study, which indicated that hypoxia-induced TXNDC5 was involved in helping proteins to fold correctly via its disulfide isomerase activity (13). Taken together, these findings suggested that TXNDC5 functions as a hypoxia-induced survival factor to regulate hypoxia-induced ROS/ER stress signaling, thereby maintaining the tumorigenesis of CRC cells under hypoxia and oxidative stress.

In conclusion, the present in vivo data demonstrated that TXNDC5 is overexpressed in CRC tissues, and this overexpression is associated with unfavorable clinicopathological features. Furthermore, the in vitro results indicated that hypoxia induces TXNDC5 expression via upregulating HIF-1 $\alpha$; this effect may promote CRC cell proliferation and survival under hypoxia, likely through inhibiting hypoxia-induced ROS/ER stress signaling. These findings suggested that TXNDC5 functions as an important stress survival factor to maintain the tumorigenesis of CRC cells under hypoxia by regulating hypoxia-induced ROS/ER stress signaling. The present study provided novel insights into the role of TXNDC5 in the tumorigenesis of CRC. 
A

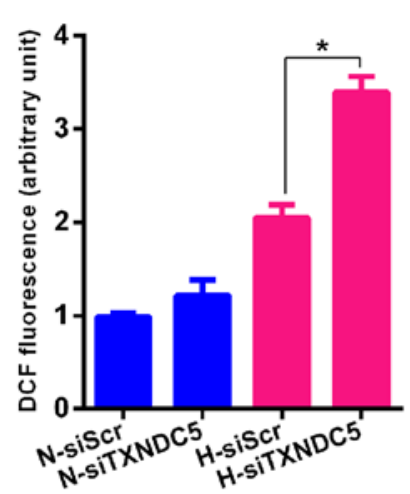

B
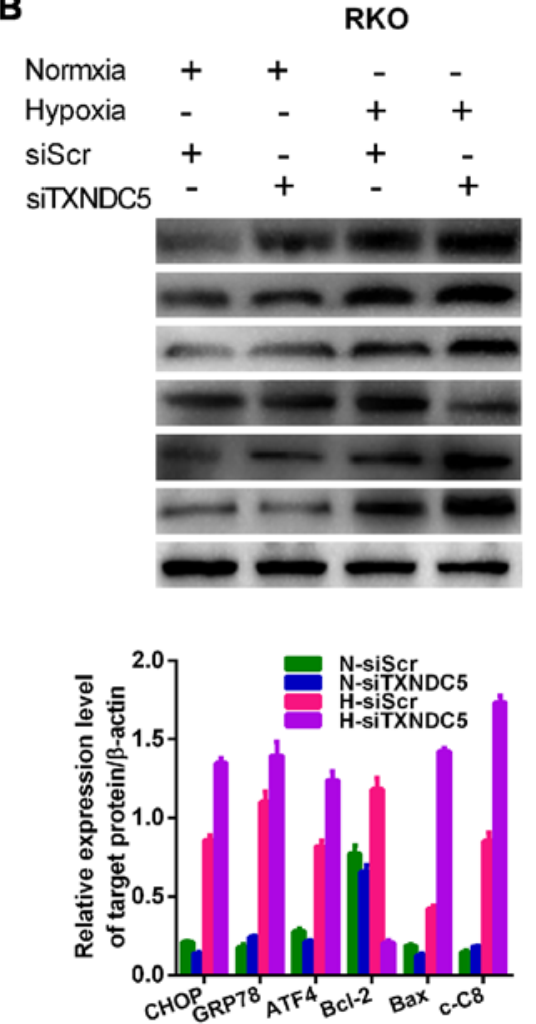

HCT-116

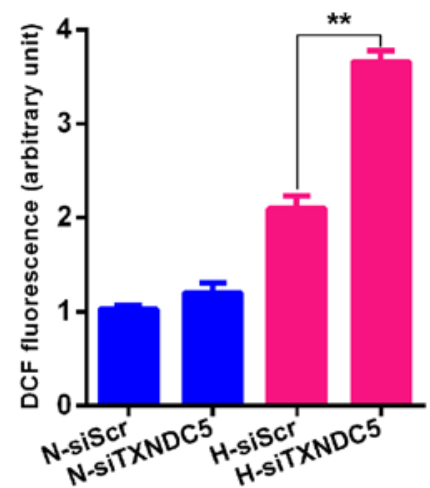

HCT-116

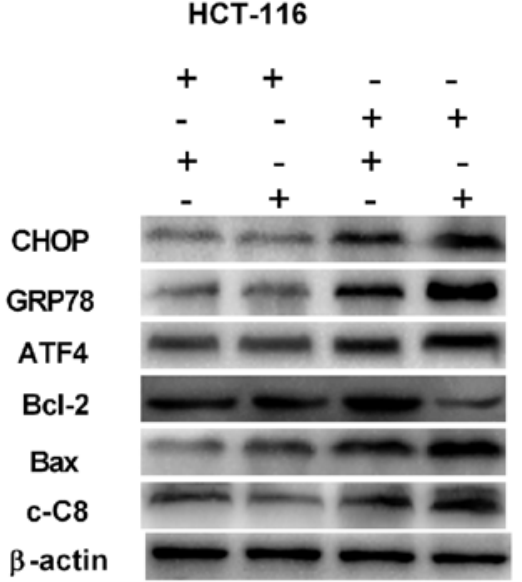

Figure 7. TXNDC5 increases the expression of ER stress and apoptotic markers. (A) RKO and HCT-116 cells were transfected with a specific siRNA (siTXNDC5) to knockdown TXNDC5. Cells transfected with siScr were used as a control. Reactive oxygen species production was measured in cells under $\mathrm{H}$ and $\mathrm{N}$ for $24 \mathrm{~h}$. ${ }^{*} \mathrm{P}=0.0004 ;{ }^{* *} \mathrm{P}=0.0010$. (B) In RKO and HCT-116 cells transfected with siTXNDC5 or siScr under H and N, western blot analyses were used to detect the protein expression levels of ER stress (CHOP, GRP78 and ATF4), apoptosis (Bax and cleaved caspase-8) and survival (Bcl-2) markers. $\beta$-actin was used as a loading control. Density of the blots was normalized against that of the $\beta$-actin blot, in order to obtain relative blot density. ${ }^{*} \mathrm{P}<0.05$. ATF4, activating transcription factor 4; Bax, Bcl-2-associated X protein; Bcl-2, B-cell lymphoma 2; c-C8, caspase-8; CHOP, CCAAT-enhancer-binding protein homologous protein; GRP78, glucose-regulated protein 78; DCF, dichlorodihydrofluorescein; ER, endoplasmic reticulum; H, hypoxia; N, normoxia; siRNA/si, small interfering RNA; siScr, scrambled control siRNA; TXNDC5, thioredoxin domain-containing 5 .

\section{Acknowledgements}

Not applicable.

\section{Funding}

The present study was funded by the Science and Technology Plan Fund of Hunan Province, P.R. China (grant nos. 2015WK3011; 2015SK20201) and the Beijing CSCO Fund (grant no. Y-MX2014-002).

\section{Availability of data and materials}

The datasets used or analyzed during the current study are available from the corresponding author on reasonable request.

\section{Authors' contributions}

FT and HP conceived and designed the experiments. FT and $\mathrm{HZ}$ wrote the article. XH and NY prepared the patient samples. FT and NY performed the experiments. HX, XZ 
and $\mathrm{XH}$ collected and analyzed the data. All authors read and approved the final manuscript.

\section{Ethics approval and consent to participate}

The present study was approved by the Medical Ethics Committee of Xiangya Hospital (Changsha, China) and all patients provided written informed consent. All experimental procedures were conducted in conformity with institutional guidelines for the care and use of laboratory animals, and protocols were approved by the Institutional Animal Care and Treatment Committee of Central South University.

\section{Consent for publication}

Not applicable.

\section{Competing interests}

The authors declare that they have no competing interests.

\section{References}

1. Zheng R, Zeng $\mathrm{H}$, Zhang S, Chen $\mathrm{T}$ and Chen W: National estimates of cancer prevalence in China, 2011. Cancer Lett 370: 33-38, 2016.

2. Pesson M, Volant A, Uguen A, Trillet K, De La Grange P, Aubry M, Daoulas M, Robaszkiewicz M, Le Gac G, Morel A, et al: A gene expression and pre-mRNA splicing signature that marks the adenoma-adenocarcinoma progression in colorectal cancer. PLoS One 9: e87761, 2014.

3. Schell MJ, Yang M, Missiaglia E, Delorenzi M, Soneson C, Yue B, Nebozhyn MV, Loboda A, Bloom G and Yeatman TJ A composite gene expression signature optimizes prediction of colorectal cancer metastasis and outcome. Clin Cancer Res 22: 734-745, 2016.

4. Keith B and Simon MC: Hypoxia-inducible factors, stem cells, and cancer. Cell 129: 465-472, 2007.

5. Saito S, Lin YC, Tsai MH, Lin CS, Murayama Y, Sato R and Yokoyama KK: Emerging roles of hypoxia-inducible factors and reactive oxygen species in cancer and pluripotent stem cells. Kaohsiung J Med Sci 31: 279-286, 2015.

6. Hotokezaka Y, van Leyen K, Lo EH, Beatrix B, Katayama I, Jin G and Nakamura T: AlphaNAC depletion as an initiator of ER stress-induced apoptosis in hypoxia. Cell Death Differ 16: $1505-1514,2009$

7. Pereira ER, Frudd K, Awad W and Hendershot LM: Endoplasmic reticulum (ER) stress and hypoxia response pathways interact to potentiate hypoxia-inducible factor 1 (HIF-1) transcriptional activity on targets like vascular endothelial growth factor (VEGF). J Biol Chem 289: 3352-3364, 2014.

8. Chevet E, Hetz C and Samali A: Endoplasmic reticulum stress-activated cell reprogramming in oncogenesis. Cancer Discov 5: 586-597, 2015.

9. Yadav RK, Chae SW, Kim HR and Chae HJ: Endoplasmic reticulum stress and cancer. J Cancer Prev 19: 75-88, 2014.

10. Clarke HJ, Chambers JE, Liniker E and Marciniak SJ: Endoplasmic reticulum stress in malignancy. Cancer Cell 25 563-573, 2014.

11. Horna-Terrón E, Pradilla-Dieste A, Sánchez-de-Diego C and Osada J: TXNDC5, a newly discovered disulfide isomerase with a key role in cell physiology and pathology. Int J Mol Sci 15: 23501-23518, 2014.

12. Sullivan DC, Huminiecki L, Moore JW, Boyle JJ, Poulsom R, Creamer D, Barker J and Bicknell R: EndoPDI, a novel protein-disulfide isomerase-like protein that is preferentially expressed in endothelial cells acts as a stress survival factor. $\mathbf{J}$ Biol Chem 278: 47079-47088, 2003.

13. Kojima R, Okumura M, Masui S, Kanemura S, Inoue M, Saiki M, Yamaguchi H, Hikima T, Suzuki M, Akiyama S, et al: Radically different thioredoxin domain arrangement of ERp46, an efficient disulfide bond introducer of the mammalian PDI family. Structure 22: 431-443, 2014.
14. Funkner A, Parthier C, Schutkowski M, Zerweck J, Lilie H, Gyrych N, Fischer G, Stubbs MT and Ferrari DM: Peptide binding by catalytic domains of the protein disulfide isomerase-related protein ERp46. J Mol Biol 425: 1340-1362, 2013.

15. Chang X, Xu B, Wang L, Wang Y, Wang Y and Yan S: Investigating a pathogenic role for TXNDC5 in tumors. Int $\mathrm{J}$ Oncol 43: 1871-1884, 2013.

16. Wang Y, Ma Y, Lü B, Xu E, Huang Q and Lai M: Differential expression of mimecan and thioredoxin domain-containing protein 5 in colorectal adenoma and cancer: a proteomic study. Exp Biol Med (Maywood) 232: 1152-1159, 2007.

17. Shen H, Huang J, Pei H, Zeng S, Tao Y, Shen L, Zeng L and $\mathrm{Zhu} \mathrm{H}$ : Comparative proteomic study for profiling differentially expressed proteins between Chinese left- and right-sided colon cancers. Cancer Sci 104: 135-141, 2013.

18. Affer M, Chesi M, Chen WD, Keats JJ, Demchenko YN, Tamizhmani K, Garbitt VM, Riggs DL, Brents LA, Roschke AV, et al: Promiscuous MYC locus rearrangements hijack enhancers but mostly super-enhancers to dysregulate MYC expression in multiple myeloma. Leukemia 28: 1725-1735, 2014.

19. Livak KJ and Schmittgen TD: Analysis of relative gene expression data using real-time quantitative PCR and the $2(-\Delta \Delta \mathrm{C}(\mathrm{T}))$ method. Methods 25: 402-408, 2001.

20. Dang DT, Chen F, Gardner LB, Cummins JM, Rago C, Bunz F, Kantsevoy SV and Dang LH: Hypoxia-inducible factor-1alpha promotes nonhypoxia-mediated proliferation in colon cancer cells and xenografts. Cancer Res 66: 1684-1936, 2006.

21. Shweta, Mishra KP, Chanda S, Singh SB and Ganju L: A comparative immunological analysis of $\mathrm{CoCl}_{2}$ treated cells with in vitro hypoxic exposure. Biometals 28: 175-185, 2015.

22. Neufert C, Becker C and Neurath MF: An inducible mouse model of colon carcinogenesis for the analysis of sporadic and inflammation-driven tumor progression. Nat Protoc 2: 1998-2004, 2007.

23. George AL, Rajoria S, Suriano R, Mittleman A and Tiwari RK: Hypoxia and estrogen are functionally equivalent in breast cancer-endothelial cell interdependence. Mol Cancer 11: 80, 2012.

24. Wang L, Zheng Y, Xu H, Yan X and Chang X: Investigate pathogenic mechanism of TXNDC5 in rheumatoid arthritis. PLoS One 8: e53301, 2013.

25. Chang X, Cui Y, Zong M, Zhao Y, Yan X, Chen Y and Han J: Identification of proteins with increased expression in rheumatoid arthritis synovial tissues. J Rheumatol 36: 872-880, 2009.

26. Vincent EE, Elder DJ, Phillips L, Heesom KJ, Pawade J, Luckett M, Sohail M, May MT, Hetzel MR and Tavaré JM: Overexpression of the TXNDC5 protein in non-small cell lung carcinoma. Anticancer Res 31: 1577-1582, 2011.

27. Mizukami Y, Kohgo Y and Chung DC: Hypoxia inducible factor-1 independent pathways in tumor angiogenesis. Clin Cancer Res 13: 5670-5674, 2007

28. Nagaraju GP, Bramhachari PV, Raghu G and El-Rayes BF: Hypoxia inducible factor- $1 \alpha$ : its role in colorectal carcinogenesis and metastasis. Cancer Lett 366: 11-18, 2015.

29. Zhang L, Hou Y, Li N, Wu K and Zhai J: The influence of TXNDC5 gene on gastric cancer cell. J Cancer Res Clin Oncol 136: 1497-1505, 2010.

30. Lee SO, Jin UH, Kang JH, Kim SB, Guthrie AS, Sreevalsan S, Lee JS and Safe S: The orphan nuclear receptor NR4A1 (Nur77) regulates oxidative and endoplasmic reticulum stress in pancreatic cancer cells. Mol Cancer Res 12: 527-538, 2014.

31. Malhotra JD and Kaufman RJ: Endoplasmic reticulum stress and oxidative stress: a vicious cycle or a double-edged sword? Antioxid Redox Signal 9: 2277-2293, 2007.

32. Clarke R, Cook KL, Hu R, Facey CO, Tavassoly I, Schwartz JL, Baumann WT, Tyson JJ, Xuan J, Wang Y, et al: Endoplasmic reticulum stress, the unfolded protein response, autophagy, and the integrated regulation of breast cancer cell fate. Cancer Res 72: 1321-1331, 2012.

33. Wang WA, Groenendyk J and Michalak M: Endoplasmic reticulum stress associated responses in cancer. Biochim Biophys Acta 1843: 2143-2149, 2014

34. Gu MX, Fu Y, Sun XL, Ding YZ, Li CH, Pang W, Pan S and Zhu Y: Proteomic analysis of endothelial lipid rafts reveals a novel role of statins in antioxidation. J Proteome Res 11: 2365-2373, 2012.

This work is licensed under a Creative Commons Attribution-NonCommercial-NoDerivatives 4.0 International (CC BY-NC-ND 4.0) License. 